\title{
EFEKTIFITAS METODE NIHSS DAN ESS DALAM MEMBUAT DIAGNOSA KEPERAWATAN AKTUAL PADA PASIEN STROKE BERAT FASE AKUT
}

\author{
Dedi Damhudi ${ }^{1,2^{*}}$, Dewi Irawaty ${ }^{3}$, Rr. Tutik Sri Hariyati ${ }^{3}$ \\ 1. Poltekes Kemenkes Pontianak Jurusan Keperawatan Singkawang, Singkawang 79123, Indonesia \\ 2. Program Studi Magister Ilmu Keperawatan Universitas Indonesia, Depok 16424, Indonesia \\ 3. Fakultas Ilmu Keperawatan Universitas Indonesia, Depok 16424, Indonesia \\ *Email:dedi_skp@yahoo.co.id
}

\begin{abstract}
Abstrak
Penelitian ini bertujuan mengidentifikasi efektifitas pengkajian metode NIHSS dan ESS dalam membuat diagnosa keperawatan aktual pada pasien stroke berat fase akut di RSUP X Jakarta. Penelitian ini menggunakan desain pra-eksperimen post-test only design (the one shot case study) dengan purposive sampling melibatkan 18 responden. Hasil menunjukkan hubungan sangat kuat berpola positif $(r=0,904)$ pada nilai NIHSS dan berpola negatif $(r=-0,912)$ pada nilai ESS $(p=1,000 ; \alpha=0,05)$. Tidak ada perbedaan efektifitas penggunaan metode NIHSS dan ESS terhadap pembuatan diagnosa keperawatan yang aktual pada pasien stroke berat fase akut. Sebagai seorang perawat di ruang unit stroke sangatlah penting untuk menguasai pengkajian metode ini dalam rangka meningkatkan mutu asuhan keperawatan sehingga mempercepat proses penyembuhan pasien.
\end{abstract}

Kata kunci: diagnosa keperawatan, efektifitas, NIHSS, ESS

Abstract

The purpose of this study was to identify the effect of NIHSS and ESS assessment method on the developing actual nursing diagnosis on the acute phase severe stroke's patient in X Hospital Jakarta. This study used experiment with post-test only design (the one shot case study), used non-random purposive sampling and involved 18 respondent. The results showed that the strong positive relationship $(r=0.904)$ for NIHSS assessment value and negative pattern $(r=-0.912)$ for ESS assessment value ( $p=1.000 ; \alpha=0.05)$. There is no significant different the effect of using NIHSS and ESS methods on developing actual nursing diagnosis on the acute phase severe stroke's patient. It is important for the nurses to be able to use both assessment methods in order to improve the quality of nursing care and shorten the recovery process of the patient.

Keywords: nursing diagnosis, effectiveness, ESS, NIHSS

\section{Pendahuluan}

Stroke atau cedera serebrovaskuler (CVA) adalah ketidaknormalan fungsi sistem saraf pusat (SSP) disebabkan oleh gangguan kenormalan aliran darah ke otak. Stroke dibagi menjadi dua, yaitu iskemik (85\%) dan perdarahan (15\%) (Smeltzer \& Bare, 2008). Stroke menyebabkan berbagai defisit neurologi, bergantung pada lokasi dan ukuran lesi. Manifestasi klinis dari stroke antara lain; kehilangan motorik, kehilangan komunikasi, gangguan persepsi, kerusakan fungsi kognitif dan efek psikologik, disfungsi kandung kemih (Lemone \& Burke, 1996; Polaski \& Tatro, 1996; Black \& Hawks, 2005; Ignatavicius \& Workman, 2006).

Data WHO pada 2007 menunjukkan bahwa sebanyak 15 juta orang menderita stroke di seluruh dunia setiap tahun. Lima juta orang mengalami kematian dan 5 juta mengalami kecacatan yang menetap (Stroke Center, 2007). Diperkirakan setiap tahun terjadi 500.000 orang penduduk Indonesia terkena serangan stroke, sekitar $25 \%$ atau 125.000 orang meninggal dan sisanya mengalami cacat ringan atau berat (Yastroki, 2007). Berdasarkan hasil catatan medis RSUP X Jakarta, Januari sampai Desember 2007, 557 pasien stroke yang terbagi menjadi stroke non hemoragik 266 orang dan stroke hemoragik 291 orang.

Menurut (AANN, 2004), waktu adalah faktor yang sangat penting dalam mengoptimalkan penanganan pasien dengan stroke. Sedangkan menurut (AHA) dan (NSA) perawatan harus dilakukan dalam waktu 36 jam pertama terkena serangan untuk mendapatkan hasil yang baik saat pasien pulang. 
Pengkajian neurologi termasuk jenis pengkajian fokus dan bersifat darurat. Hal ini dikarenakan lingkup pengkajian lebih spesifik pada sistem persarafan dengan waktu yang singkat dan dapat mengidentifikasi situasi yang menyakut penyelamatan nyawa pasien. Sampai saat ini metode yang digunakan untuk mengkaji kondisi pasien stroke fase akut adalah NIHSS dan ESS (Black \& Hawks, 2005; Edwards, 2007; Smeltzer \& Bare, 2008).

Sampai saat ini penelitian tentang efektifitas pengkajian metode NIHSS dan ESS dalam membuat diagnosa keperawatan yang aktual belum pernah dilakukan. Hal ini mendorong peneliti untuk meneliti efektifitas pengkajian neurologis dengan metode NIHSS dan ESS dalam membuat diagnosa keperawatan aktual pada pasien stroke berat fase akut.

\section{Metode}

Penelitian ini menggunakan desain pra-eksperimen postest only design (The one shot case study). Sampel dengan jumlah 18 orang, menggunakan tehnik purposive sampling. Dengan kriteria: (1) Pasien stroke berat fase akut, (2) Nilai NIHSS lebih dari 15, dan (3) Stroke hemoragik dan non hemoragik.

Prosedur pengumpulan data dilakukan dengan pengkajian yang mengunakan metode NIHSS dan ESS untuk melihat perolehan diagnosa keperawatan aktual. Analisis data menggunakan uji korelasi untuk mengetahui keeratan hubungan antara nilai NIHSS dan ESS terhadap diagnosa keperawatan aktual yang diperoleh dan uji tanda Wilcoxon untuk mengetahui efektifitas penggunaan metode NIHSS dan ESS dalam membuat diagnosa keperawatan aktual pada pasien stroke berat fase akut.

\section{Hasil}

Hasil menunjukkan nilai NIHSS rata-rata 33,06 (95\% CI: 29,63-36,48) dan nilai ESS rata-rata 19,78 (95 \% CI: 10,96 - 28,59), dengan standar deviasi nilai NIHSS 6,89 dan nilai ESS 17,73 . Nilai terendah NIHSS adalah 24, nilai ESS adalah 0 dan nilai tertinggi NIHSS adalah 41, nilai ESS adalah 47. Dari hasil estimasi interval dapat disimpulkan $95 \%$ diyakini rata-rata nilai NIHSS antara 29,63 - 36,48 dan ESS antara 29,63 - 36,48 pada pasien stroke berat fase akut.

Pada tabel 1 menunjukkan bahwa jumlah diagnosa keperawatan aktual menggunakan pengkajian metode NIHSS dan metode ESS rata-rata 9,67 buah (95\% CI: 9,43 - 9,91), dengan standar deviasi 0,485 . Perolehan diagnosa paling sedikit 9 (sembilan) buah berjumlah 6 (enam) responden dan paling banyak 10 buah berjumlah 12 responden. Dari hasil estimasi interval dapat disimpulkan 95\% diyakini rata-rata perolehan jumlah diagnosa keperawatan aktual menggunakan pengkajian metode NIHSS dan metode ESS adalah diantara 9,43 - 9,91 pada pasien stroke berat fase akut.

Tabel 2 menunjukkan bahwa ada hubungan bermakna antara nilai NIHSS dengan diagnosa keperawatan aktual NIHSS. Hubungan nilai NIHSS dengan perolehan diagnosa keperawatan sangat kuat atau sempurna dan mempunyai pola positif. Artinya, semakin besar nilai NIHSS semakin banyak diagnosa keperawatan aktual yang diperoleh pada pasien stroke berat fase akut $(\mathrm{r}=0,904$; $\mathrm{p}=0,0005)$.

Tabel 1. Distribusi Diagnosa Keperawatan Aktual Menggunakan Metode NIHSS dan ESS

\begin{tabular}{lccccccc}
\hline \multicolumn{1}{c}{ Variabel } & \multirow{2}{*}{ Mean } & \multirow{2}{*}{$\boldsymbol{S D}$} & $\boldsymbol{m i n}$ & $\mathbf{n}^{\text {Jumlah }}$ & $\mathbf{m a x}$ & $\mathbf{n}$ & \multirow{2}{*}{$\mathbf{9 5}$ \% CI } \\
\hline Diagnosa NIHSS & 9,67 & 0,485 & 9 & 6 & 10 & 12 & $9,43-9,91$ \\
Diagnosa ESS & 9,67 & 0,485 & 9 & 6 & 10 & 12 & $9,43-9,91$ \\
\hline
\end{tabular}


Tabel 3 menunjukkan ada hubungan bermakna antara nilai ESS dengan diagnosa keperawatan aktual ESS. Hubungan nilai ESS dengan perolehan diagnosa keperawatan sangat kuat atau sempurna dan berpola negatif artinya semakin kecil nilai ESS semakin banyak diagnosa keperawatan aktual yang diperolah pada pasien stroke berat fase akut $(r=-0,912 ; p=0,0005)$.

Tabel 4 diperoleh jumlah diagnosa keperawatan aktual menggunakan pengkajian metode NIHSS dan metode ESS rata-rata 9,67 buah, dengan SD 0,485 . Perolehan diagnosa paling sedikit 9 buah dan paling banyak 10 buah. Penelitian ini menyimpulkan bawah tidak ada perbedaan bermakna dalam penggunaan metode NIHSS dan metode ESS untuk pembuatan diagnosa keperawatan aktual pada pasien stroke $(p=1,000 ; \alpha=0,005)$.

\section{Komponen Penilaian Metode NIHSS dan ESS}

Pada tabel 5 menunjukkan bahwa komponen pemeriksaan pada NIHSS juga terdapat pada ESS. Dapat disimpulkan komponen penilaian metode NIHSS dan ESS adalah sama.

\section{Pembahasan}

\section{Nilai NIHSS dan ESS}

Analisis data sebelumnya, didapat nilai tertinggi NIHSS 41 dan terendah ESS 0. Hasil analisis juga didapatkan nilai terendah NIHSS 24 dan tertinggi ESS 47, menunjukkan kondisi pasien mengalami stroke berat dengan tingkat kesadaran somnolen sampai prekoma.

Tabel 2. Korelasi nilai NIHSS terhadap Diagnosa Keperawatan Aktual Menggunakan Metode NIHSSNilai NIHSS

\begin{tabular}{lccc}
\hline & Variabel & $\begin{array}{c}\text { Diagnosa } \\
\text { NIHSS }\end{array}$ & $\begin{array}{c}\text { Nilai } \\
\text { NIHSS }\end{array}$ \\
\hline $\begin{array}{l}\text { Diagnosa } \\
\text { NIHSS }\end{array}$ & Kor elasi Pearson & 1 & $0,904(* *)$ \\
& $\mathrm{p}$ & & 0,000 \\
Nilai & Kor elasi Pearson & $0,904(* *)$ & 1 \\
NIHSS & $\mathrm{p}$ & 0,000 & \\
& &
\end{tabular}

Pada pasien stroke berat dengan nilai NIHSS di atas 22 sangat beresiko tinggi terjadinya pendarahan dan hasil akhir yang buruk sehingga akan mengakibatkan gangguan neurologi, seperti penurunan kesadaran somnolen sampai dengan koma, hemianopsia, hemiparise, hemiplegi, ataksia, disartria, disphagia, parestesia, apasia, kehilangan memori dan intelektual, dan emosi tidak stabil (Black \& Hawks, 2005; Smeltzer \& Bare, 2008). Kondisi seperti ini memberikan tanda pasien memerlukan perawatan intensif seperti di ruangan ICU atau unit stroke dan dilakukan pemeriksaan NIHSS 1 jam sekali untuk mencegah kerusakan saraf yang lebih parah dan kematian (AANN, 2004).

Gangguan neurologi yang terjadi akibat stroke, tergantung pada lokasi lesi dan ukuran area infark yang terjadi. Menurut penelitian Bamford, et al. (1991), yang mengatakan bahwa dari 675 pasien yang mendapat serangan stroke pertama dapat dikelompokkan menjadi Total Anterior Circulation Infarct (TACI) 92 orang (17\%), Partial Anterior Circulation Infarct (PACI) 185 orang (34\%), Posterior Circulation Infarct (POCI) 129 orang (24\%) dan Lacunar Infarct (LACI) 137 orang (25 $\%$ ). Sedangkan hasil penelitian Orgogozo, et al. (1983) yang menyatakan bahwa pasien yang mengalami stroke 85 - 95\% akan menderita kekacauan mental, gangguan penglihatan, dan gangguan sensori.

\section{Jumlah Diagnosa Aktual dengan Metode NIHSS dan ESS}

Jumlah diagnosa keperawatan aktual pada pasien stroke berat fase akut sangat erat kaitannya dengan hasil pengkajian menggunakan metode NIHSS dan ESS. Semangkin tinggi nilai NIHSS semakin banyak diagnosa aktual yang akan diperoleh dan semakin rendah nilai ESS semakin banyak diagnosa aktual yang akan diperoleh. Hubungan yang sangat kuat atau sempurna antara nilai NIHSS dengan diagnosa keperawatan aktual terlihat pada $\mathrm{r}=0,904$ dan nilai ESS dengan diagnosa keperawatan aktual terlihat pada $\mathrm{r}=-0,912$. 
Tabel 3. Korelas nilai ESS terhadap Diagnosa Keperawatan Aktual Menggunakan Metode ESS

\begin{tabular}{lccc}
\hline \multicolumn{1}{c}{ V ariabel } & $\begin{array}{c}\text { Diagnosa } \\
\text { NIHSS }\end{array}$ & $\begin{array}{c}\text { Nilai } \\
\text { NIHSS }\end{array}$ \\
\hline $\begin{array}{l}\text { Diagnosa } \\
\text { NIHSS }\end{array}$ & Korelasi Pearson & 1 & $-0,91(* *)$ \\
& $\mathrm{p}$ & & 0,000 \\
Nilai & Korelasi Pearson & $-0,91(* *)$ & 1 \\
NIHSS & $\mathrm{p}$ & 0,000 & \\
& &
\end{tabular}

Hal ini terlihat dari analisis data sebelumnya yaitu pada pasien dengan tingkat kesadaran somnolen akan memiliki nilai NIHSS antara $24-25$ dan nilai ESS antara 41 - 47 akan mempunyai 9 diagnosa aktual. Sedangkan pada pasien dengan tingkat kesadaran prekoma dan koma akan memiliki nilai NIHSS antara $32-41$ dan nilai ESS antara $0-18$ akan mempunyai 10 diagnosa aktual.

Menurut Black dan Hawks (2005); Smeltzer dan Bare (2008); yang menyatakan bahwa pada kondisi prekoma dan koma komponen penilaian yang mengalami gangguan antara lain: derajat kesadaran, gerakan mata konyugat horizontal, lapangan pandang, paresis wajah, motorik lengan dan kaki, ataksia anggota badan, sensorik, bahasa, disartria dan unilateral negleg. Semua penilaian komponen NI-HSS dan ESS terisi penuh dengan nilai maksimal sehingga diagnosa keperawatan aktual yang diperoleh 10 buah. Sedangkan pada kondisi somnolen semua penilaian komponen NIHSS dan ESS terisi penuh tetapi nilainya tidak maksimal sehingga diagnosa keprawatan aktual yang diperoleh 9 buah.

Menurut (Hickey, 2003) mengatakan masalah keperawatan yang akan mucul pada pasien stroke berat fase akut dengan penurunan tingkat kesadaran adalah; gangguan bersihan jalan nafas, perubahan persepsi atau sensori (penglihatan, perabaan, kinestetik), gangguan komunikasi verbal, gangguan mobilitas fisik, gangguan pola eliminasi urin dan alvi, gangguan proses pikir, dan ketidakmampuan merawat diri sendiri.

\section{Efektifitas penggunaan metode NIHSS dan ESS}

Analisis terdahulu menunjukkan perolehan jumlah diagnosa aktual menggunakan metode NIHSS dan metode ESS sama banyaknya. Setelah dianalisis lebih lanjut didapatkan bawah metode NIHSS dan ESS sama baiknya untuk merumuskan diagnosa aktual pada pasien stroke berat fase akut. Hal ini menunjukkan tidak ada perbedaan efektifitas penggunaan metode NIHSS dan metode ESS terhadap pembuatan diagnosa keperawatan yang aktual pada pasien stroke fase akut pada.

Persamaan efektifitas pengkajian pada metode NIHSS dan ESS disebabkan oleh persamaan komponen penilaian yang terdiri dari tingkat kesadaran, gerakan mata konyugat horizontal, lapangan pandang, paresis wajah, motorik lengan, motorik kaki, ataksia anggota badan, sensorik, bahasa, disartria dan unilateral negleg. Walaupun ada sedikit perbedaan penulisan kalimat tapi artinya sama seperti pada NIHSS komponen paresis wajah, ataksia dan bahasa terbaik pada ESS komponen gerakan wajah, gaya berjalan dan bicara sehingga dapat disimpulkan pemeriksaan ini sama.

Hasil analisis diatas sejalan dengan hasil penelitian Berger, et al. (1999) menyatakan penggunaan metode NIHSS dapat digunakan untuk melihat kondisi pasien stroke fase akut dengan tingkat reabilitas mean kappa NIHSS 0,80 dan ESS 0,79. Hasil penelitian ini menunjukkan keakuratan kedua metode ini hampir sama sehingga hasil dari kedua metode pengkajian ini juga akan sama.

Tabel 4. Efektifitas Metode NIHSS dan ESS terhadap Diagnosa Keperawatan Aktual

\begin{tabular}{lcccc}
\hline Variabel & Mean & SD & Min-Max & p \\
\hline Diagnosa NIHSS & 9,67 & 0,485 & $9-10$ & 1,000 \\
Diagnosa ESS & 9,67 & 0,485 & $9-10$ & 1,000 \\
\hline
\end{tabular}


Penelitian ini sejalan dengan hasil penelitian Adams, et al. (1999), dimana metode NIHSS didapatkan OR 3,1 (95 \% CI: antara 1,5-6,4). Penelitian ini menyimpulkan metode NIHSS sangat bagus memprediksi hasil akhir pasien yang menderita stroke dari fase akut sampai fase pemulihan. Sedangkan hasil penelitian Loewen dan Anderson (1990), mengatakan bahwa penggunaan metode ESS mempunyai nilai korelasi $(\mathrm{r}=0,83)$ terhadap Barthel Index. Hal ini menunjukkan bahwa ada hubungan yang signifikan antara nilai ESS terhadap Barthel Index artinya adalah metode ESS dapat menilai kemampuan aktivitas sehari-hari pasien dengan baik.

Menurut Black dan Hawks (2005); Smeltzer dan Bare (2008), mengatakan bahwa pengkajian dengan metode NIHSS dan ESS dilakukan dengan 3 (tiga) teknik yaitu observasi, wawancara dan pemeriksaan fisik. Pada saat pelaksanaan penelitian ditemukan penilaian pengkajian metode NIHSS dan ESS pada pasien stroke berat fase akut tidak selamanya dilakukan dengan tiga teknik sekaligus. Pada kondisi koma pemeriksaan hanya dilakukan dengan teknik observasi dan pemeriksaan fisik. Hal ini disebabkan karena pada pasien dalam keadaan koma sulit untuk melakukan teknik wawancara.

\section{Kesimpulan}

Pengkajian dengan metode NIHSSS dan ESS sangat baik untuk melihat perkembangan pasien stroke fase akut. Terdapat hubungan yang sangat kuat atau sempurna antara nilai NIHSS dan ESS terhadap diagnosa aktual yang diperoleh. Tidak ada perbedaan efektifitas pengkajian metode NIHSS dan ESS dalam membuat diagnosa keperawatan aktual pada pasien stroke berat fase akut. Pengkajian metode NIHSS dan ESS pada pasien koma tidak dapat dilakukan dengan tiga teknik sekaligus (wawancara, observasi, pemeriksaan fisik) tetapi bisa dilakukan dengan dua teknik yaitu observasi dan pemeriksaan fisik.

Disarankan menggunakan metode NIHSS atau ESS sebagai salah satu cara dalam melakukan pengkajian system saraf pada pasien stroke karena dengan metode ini hasil pengkajian akan lebih akurat dan diagnosa aktual yang muncul akan lebih tepat. Perlu adanya sosialisasi dan pelatihan yang intensif tentang manfaat pengkajian dan kemudahan merumuskan diagnosa keperawatan yang tepat pada pasien stroke berat fase akut menggunakan pengkajian metode NIHSS dan ESS.

Sebagai informasi awal untuk penelitian selanjutnya seperti, efektifitas pengkajian menggunakan metode NIHSS dan ESS dalam pembuatan diagnosa keperawatan aktual pada asuhan keperawatan pasien dengan stroke ringan dan sedang fase akut (TG, RS, EF).

Tabel 5. Komponen penilaian NIHSS dan ESS

\begin{tabular}{|c|c|}
\hline Kompon en NIHSS & Komponen ESS \\
\hline $\begin{array}{l}\text { - Derajat kesadaran } \\
\text { - Menjawab pertanyaan } \\
\text { - Mengikuti perintah } \\
\text { - Gerakan mata konyugat } \\
\text { horizontal }\end{array}$ & $\begin{array}{l}\text { - Derajat kesadaran } \\
\text { - Pengertian/ Mengikuti } \\
\text { perintah } \\
\text { - Gerakan mata konyugat } \\
\text { horizontal }\end{array}$ \\
\hline $\begin{array}{l}\text { - Lapangan pandang } \\
\text { - Unilateral negleg } \\
\text { - Paresis wajah, Sensorik }\end{array}$ & $\begin{array}{l}\text { - Lapangan pandang } \\
\text { - Gerakan wajah }\end{array}$ \\
\hline $\begin{array}{l}\text { - Motorik lengan kanan } \\
\text { - Motorik lengan kiri }\end{array}$ & 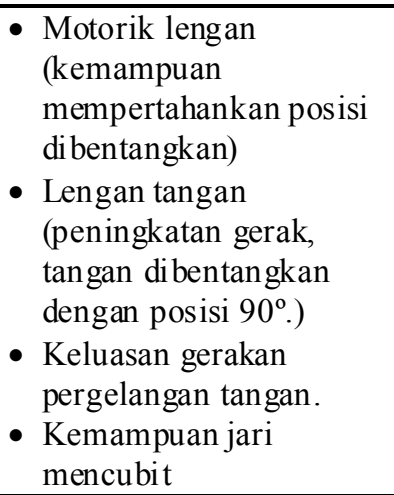 \\
\hline $\begin{array}{l}\text { - Motorik tungkai kanan } \\
\text { - Motorik tungkai kiri }\end{array}$ & $\begin{array}{l}\text { - } \text { Motorik kaki } \\
\text { (mempertahankan posisi) } \\
\text { - Kaki (fleksi) } \\
\text { - Dorso fleksi pada kaki }\end{array}$ \\
\hline $\begin{array}{l}\text { - Ataksia anggota badan } \\
\text { - Bahasa terbaik } \\
\text { - Disartria }\end{array}$ & $\begin{array}{l}\text { - Gaya berjalan } \\
\text { - Bicara }\end{array}$ \\
\hline $\begin{array}{c}\text { Total Skor NIHSS: } \\
0-42\end{array}$ & $\begin{array}{c}\text { Total Skor ESS: } \\
0-100\end{array}$ \\
\hline
\end{tabular}




\section{Referensi}

AANN. (2004). Guide to the care of the patient with ischemic Stroke. USA: PDL BioPharma.

Adams, H.P Jr., Davis, P.H., Leira, E.C., Chang, K.C., Bendixen, B.H., Clarke, W.R., Woolson, R.F., \& Hansen, M.D1. (1999). Baseline NIHSS stroke scale score strongly predicts outcome after stroke: A report of the trial of org 10172 in acute stroke treatment (TOAST). Neurology, 53 (1), 126-131.

Bamford, J., Sandercock, P., Dennis, M., Burn, J., \& Warlow, C. (1991). Classification and natural history of clinically identifiable subtypes of cerebral infarction. Lancet, 337 (8756), 15211526.

Black, M.J., \& Hawks, H.J. (2005). Medical-surgical nursing: Clinical management for positive outcome (7th Ed.). St.Louis: Elsevier Inc.

Berger, K., Weltermann, B., Kolominsky-Rabas, P., Meves, S., Heuschmann, P., Böhner, J., Neundörfer, B., Hense, H.W., \& Büttner, T. (1999). The reliability of stroke scales: The German version of NIHSS, ESS, and ranking scales. Fortschr Neurol Psychiatri, 67 (2), 81-93.

Edwards. (2007). Acute assessment scales. Diperoleh dari http://www.strokecenter.org/trials/scales/ index.htm.

Hickey, V.J. (2003). The clinical practice of neurological and neurosurgical nursing (5th Ed.). Philadelphia: Lippincott William \& Wilkins.
Ignatavicius, D.D., \& Workman, M.L. (2006). Medical-surgical nursing: Critical thingking for colaborative care. St. Louis: Elsevier Inc.

Loewen, S.C., \& Anderson, B.A. (1990). Predictors of stroke outcome using objective measurement scales. Stroke, 21 (1), 78-81.

Lemone, P., \& Burke, M.K. (1996). Medicalsurgical nursing: Critical thinking in client care. St. Louis: Cummings Publishing Company Inc.

Orgogozo, J.M., Capildeo, R., Anagnostou, C.N., Juge, O., Péré, J.J., Dartigues, J.F., Steiner, T.J., Yotis, A., \& Rose, F.C. (1983). Development of a neurological score for the clinical evaluation of sylvian infarctions. Press Med, 12 (48), 30393044.

Polaski, L.A., \& Tatro, E.S. (1996). Luckmann's core principles and practice of medicalsurgical nursing (1st Ed.). Philadelphia: WB. Sauders Company.

Smeltzer, S.C., Bare, B.G., Cheever, K.H., \& Hinkle, J. (2008). Brunner \& Suddarth's texbook of medical-surgical nursing (11th Ed.). Philadelphia: Lippincott and Wilkins.

Stroke Center. (2007). Population stoke in the world. Diperoleh dari http://www.strokecenter.org/ patients/ stats.htm.

Yastroki. (2002). Tahun 2020, penderita stroke meningkat 2 kali. Diperoleh dari http://www. yastroki.or.id/read.php?id=319. 